\title{
TEKNIK PEWARNAAN ALAM ECO PRINT DAUN UBI DENGAN PENGGUNAAN FIKSATOR KAPUR, TAWAS DAN TUNJUNG
}

\author{
Bayu Wirawan D. S.,* dan M. Alvin \\ Program Studi Teknik Batik, Politeknik Pusmanu \\ Jalan Raya Karangdowo No.9 Kedungwuni Pekalongan \\ Korespondensi: bayuwirawands@ politeknikpusmanu.ac.id
}

\begin{abstract}
Natural dyes is a coloring technique using raw materials from nature, the absorbed color will blend with the fibers in the fabric. Every plant has the potential to be fabric dyes. The ecoprint and ecodyeing technique is defined as the process of transferring colors and shapes to fabric through direct contact. The purpose of this study was to compare the results of the natural coloring technique of sweet potato leaf ecoprint with the use of chalk, alum and tunjung fixators. The natural coloration of ecoprint sweet potato leaves with chalk, alum and tunjung fixators, has several different results. From the results of the study concluded that the manufacture of ecoprint fabric with sweet potato leaves must use a fixing agent as a color locking agent and chalk fixator is superior to be used in the fixation process because if the fabric is washed it does not fade easily.
\end{abstract}

Keywords: Natural dyes, Ecoprint, Fixator

\section{PENDAHULUAN}

Natural Dyes atau pewarnaan alam merupakan satu dari sekian banyak cara yang potensial untuk pengembangan eco fashion. Teknik ini merupakan teknik pewarnaan dengan menggunakan bahan baku dari alam, warna yang terserap akan menyatu dengan serat yang ada pada kain. Setiap tumbuhan memiliki potensi untuk dijadikan bahan pewarna kain. Tentu saja warna yang dihasilkan akan berbeda dari tiap tanaman. Hasil bergantung pada musim, intensitas hujan, udara (yang sudah tercemar polusi), kualitas tanah. Karakter tumbuhan yang dipilih untuk dijadikan bahan pewarnaan pun akan berpengaruh pada hasil akhir. Daun yang masih segar, sudah kering, bahkan daun yang baru jatuh pun akan memberi hasil berbeda (Flint, 2008).

Seiring berkembangnya zaman, teknik pewarnaan kain dengan bahan alam berkembang dengan berbagai temuan baru, salah satunya adalah teknik ecodyeing dan ecoprinting. Teknik ecoprint dan ecodyeing diartikan sebagai proses mentransfer warna dan bentuk ke kain melalui kontak langsung. Flint mengaplikasikan teknik ini dengan cara menempelkan tanaman yang memiliki pigmen warna pada kain berserat alami yang kemudian direbus atau dikukus dalam kuali besar. Tanaman yang digunakan merupakan tanaman yang memiliki sensitivitas tinggi terhadap panas, karena hal tersebut merupakan faktor penting dalam mengekstraksi pigmen warna.

Kontak langsung antara tumbuhan dan bahan utama merupakan prinsip kerja utama pada metode ecodyeing dan printing. Berbagai elemen dari tumbuhan dapat digunakan seperti daun, bunga, batang, biji, akar atau kulit kayu. Tumbuhan di setiap musimnya akan memiliki pigmen berbeda dan menghasilkan warna yang berbeda pada kain. Metode ini tidak berfokus pada pakem hasil yang telah ditetapkan. Karena kemungkinan pengembangan teknik ini sangat luas dan beragam. Berbagai macam tumbuhan yang tidak digolongkan sebagai pewarna alam ternyata dapat menjadi pewarna alam. 
Tanaman yang digunakan pada penelitian ini adalah daun ubi jalar, karena ubi jalar banyak tumbuh di Indonesia, khususnya khususnya di Pulau Jawa sehingga mudah didapat. Pada bagian daun ubi jalar mempunyai tekstur yang baik dan tebal pada bagian tulang daunnya sehingga dalam proses pembuatan ecoprint lebih terlihat motifnya.

Pewarna alam tidak semua akan meresap dengan sempurna di kain apabila tidak menggunakan zat pembantu. Zat pembantu yang akan digunakan adalah tawas, tunjung dan kapur .

\section{RUMUSAN MASALAH}

Rumusan masalah dari penelitian ini adalah apakah daun ubi jalar bisa digunakan sebagai media utama kain eco print dengan penggunaan fiksator kapur, tawas dan tunjung.

\section{TINJAUAN PUSTAKA}

\subsection{Ecoprint}

Alam dapat menjadikan sumber inspiransi, untuk berkarya. Untuk itu, pemanfaatan bahan alam sebagai bahan utama, untuk pembuatan suatu karya salah satunya adalah kain Eco print, eco berasal dari kata ekosistem (alam) dan print yang artinya mencetak, kain yang diwarnai menggunakan pewarna alami dan mencetak motif dari daun secara manual dengan cara ditempel dan dipukul sampai timbul motif daun tersebut (Felix, 2002).

\subsection{Daun Ubi Jalar}

Ubi jalar ungu (Ipomoea batatas L.,) merupakan tumbuhan merambat yang hidup di segala cuaca, di daerah pegunungan maupun di pantai.

\subsection{Fiksator}

Tujuan dilakukan fiksasi yaitu untuk mengunci zat warna alam golongan mordan serta berfungsi memberikan efek warna (arah warna) yang berbeda-beda sesuai dengan zat fiksasi yang digunakan (Sardjono, 2010). Bahan fiksasi perlu dipilih dari bahan yang ramah lingkungan dan bersifat non-toksik supaya tidak menjadi masalah pada lingkungan (Kuniasari dan Maharani, 2015 dalam Pujilestari, 2015:8). Bahan pengikat yang sering digunakan antara lain : tawas (Alum), kapur $\left(\mathrm{CaCO}_{3}\right)$ dan tunjung (Fe SO4).

\section{METODOLOGI PENELITIAN}

\subsection{Bahan yang digunakan}

\subsubsection{Bahan Utama}

Daun ubi jalar sebagai media utama untuk dijadikan uji coba dalam perbandingan hasil fiksasi antara tawas kapur dan tunjung. 


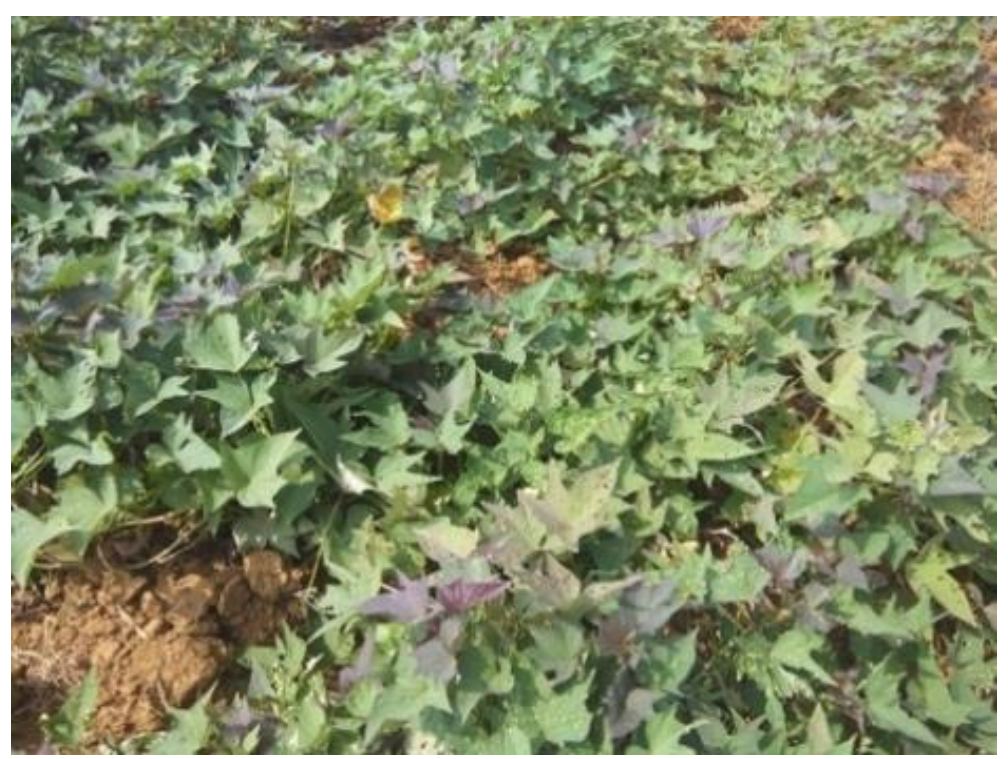

Gambar 1 Tanaman ubi jalar

\subsubsection{Bahan fiksator}

Bahan Fiksator yang digunakan adalah kapur, tawas dan tunjung.
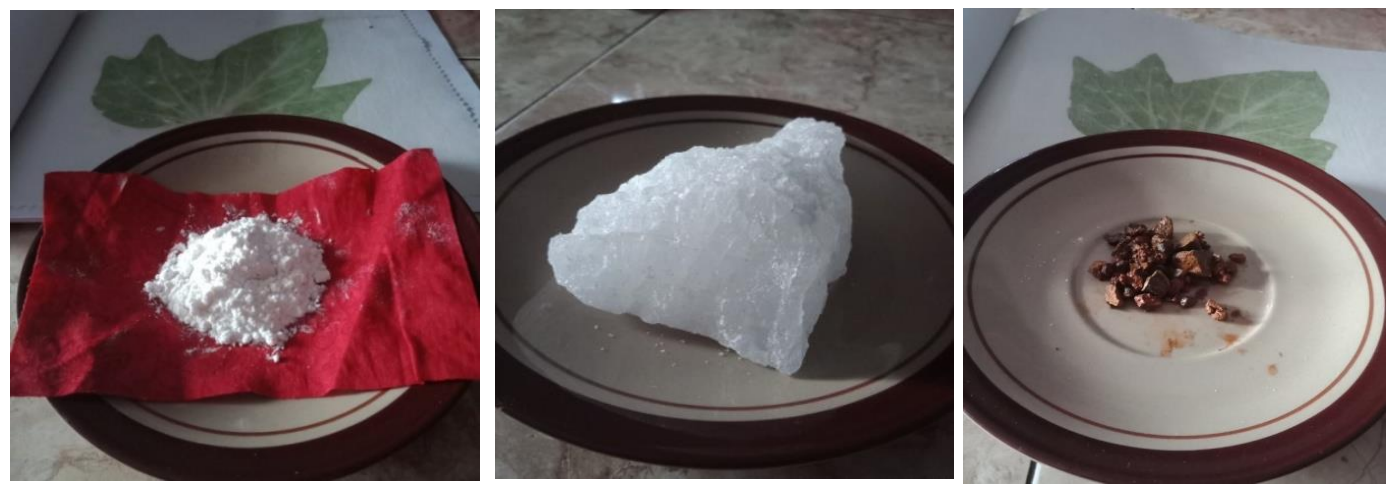

Gambar 2 Kapur, tawas dan tunjung

\subsection{Proses Pembuatan}

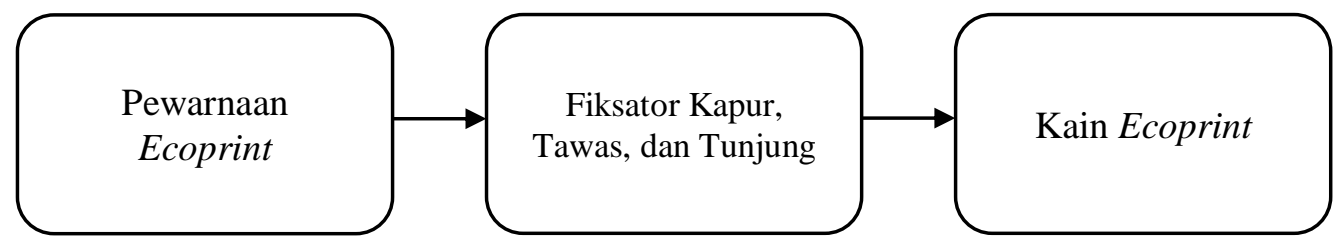

Gambar 3 Proses Pembuatan

\section{HASIL DAN PEMBAHASAN}

\subsection{Langkah-langkah Pembuatan Kain Ecoprint}

1) Siapkan kain polos yang sudah dicuci dengan air.

2) Siapkan daun ubi jalar yang sudah dicuci.

3) Lalu letakan daun ubi di atas kain dan ditutup dengan kain polos.

4) Pukul menggunakan palu karet sampai sari daun keluar dan menempel pada kain.

5) Setelah ditutup kain dan dipukul dengan palu, kain yang telah ditempeli daun ubi jalar dilapisi dengan plastik. 
6) Proses selanjutnya kain yang telah dilapisi plastik tersebut digulung dan diikat dengan rafia dan dikukus.

7) Selesai dikukus, kain ecoprint dibuka dari ikatan kemudian dikeringkan.

8) Kain yang telah jadi selanjutnya difiksasi menggunakan kapur, tawas, atau tunjung.

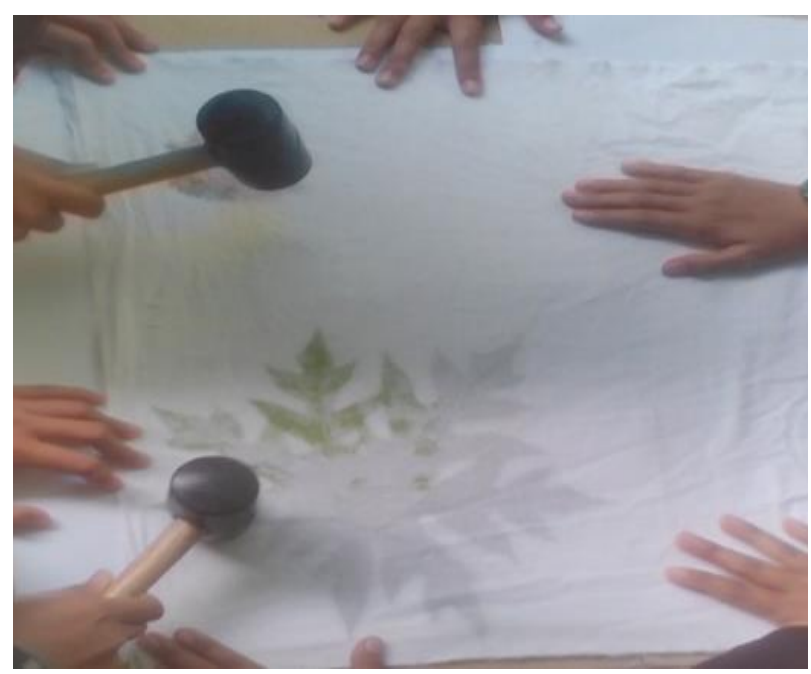

Gambar 4 Proses pembuatan kain ecoprint

\subsection{Hasil}

Berikut adalah hasil pewarnaan alam teknik ecoprint daun ubi jalar dengan penggunaan fiksator kapur, tawas dan tunjung ditunjukkan pada Gambar 5.

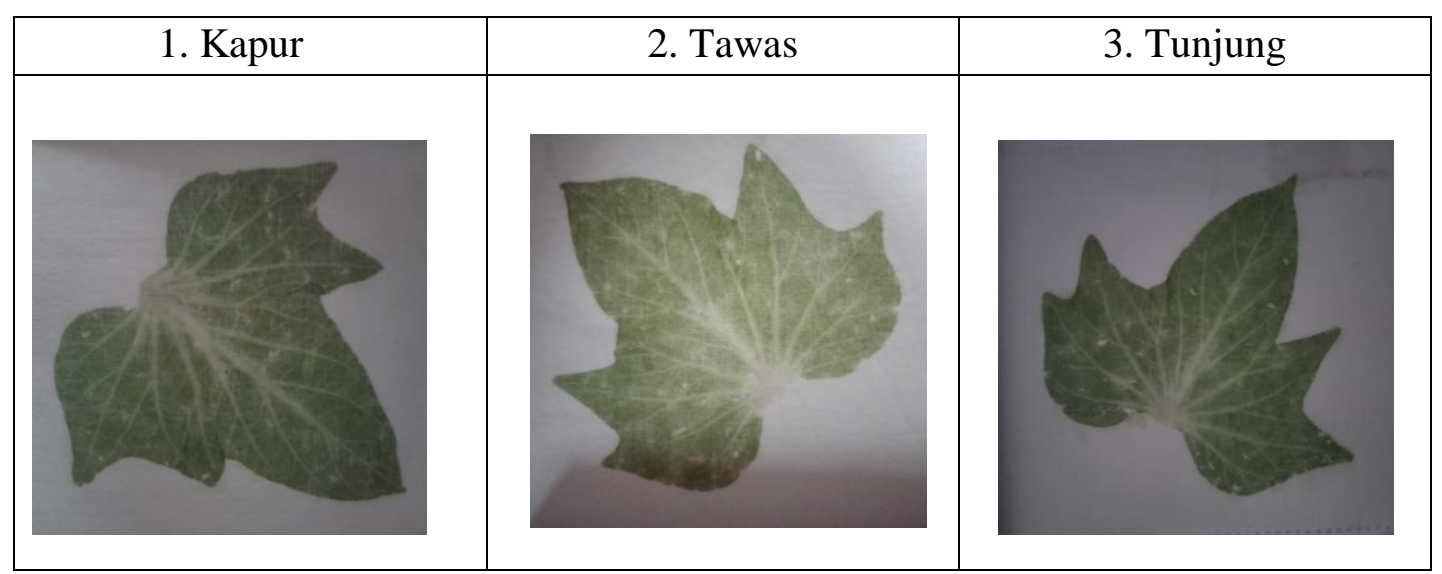

Gambar 5 Hasil Pewarnaan

1) Fiksator kapur hasilnya lebih muda dan apabila kain dicuci tidak mudah luntur.

2) Fiksator tawas warnanya lebih muda dari kapur dan tunjung, lebih mudah luntur apabila kain dicuci, tetapi mempunyai keunggulan kain terlihat lebih putih di antara fiksator kapur dan tunjung.

3) Fiksator tunjung mempunyai keunggulan warna paling kuat diantara tawas dan kapur ketika dicuci kain tidak mudah luntur tetapi mempunyai hasil yang kurang baik karena tunjung akan membuat warna kain terlihat lebih kusam. 


\section{KESIMPULAN}

Berdasarkan penelitian ini maka dapat disimpulkan :

1) Pembuatan kain ecoprint dengan daun ubi jalar harus menggunakan zat pembantu fiksator sebagai zat pengunci warna.

2) Dari hasil penelitian fiksator kapur yang lebih unggul digunakan dalam proses fiksasi, karena apabila kain dicuci tidak mudah luntur.

\section{SARAN}

Perlu dilakukan proses uji ketahanan luntur untuk penelitian selanjutnya.

\section{DAFTAR PUSTAKA}

Felix (2002), Teknik Eco Dyeing dengan Memanfaatkan Tanaman sebagai Pewarna Alam

Flint, India, (2008) Eco Colour, Murdoch Books, Australia.

Pujilestari, T. 2015. Review : Sumber dan Pemanfaatan Zat Warna Alam untuk Keperluan

Industri. Jurnal Dinamika Kerajinan dan Batik, Vol. 32 (2) : 93-106. Yogyakarta:

Sardjono. 2010. Teknologi Pewarnaan Batik Zat Warna Alam. Yogyakarta: Balai Besar Kerajinan dan Batik.

Thamrin Usman (2005) Esterifikasi Asam Lemak dari Limbah Kelapa Sawit menggunakan Katalis Tawas (Vol 9, No.3, 2009, Hal 474-478, Indonesia Journal of Chemistry). 